\title{
Article
}

\section{The Impact of Social Network Site Addiction on Depression in Chinese Medical Students: A Serial Multiple Mediator Model Involving Loneliness and Unmet Interpersonal Needs}

\author{
Ruijie Gong ${ }^{1,2,+}$, Yinghuan Zhang ${ }^{1,+}{ }^{+}$, Rusi Long ${ }^{1}$, Rui Zhu ${ }^{1}$, Sicong Li ${ }^{1}$, Xinyi Liu ${ }^{1}$, Suping Wang ${ }^{3, *}$ \\ and Yong Cai ${ }^{1, *}$
}

1 School of Public Health, Shanghai Jiao Tong University School of Medicine, Shanghai 200025, China; cynthiadt0717@163.com (R.G.); zhangyinghuan0516@163.com (Y.Z.); rusi-long@sjtu.edu.cn (R.L.); lily1998225@gmail.com (R.Z.); m15026658167@163.com (S.L.); czlxy0203@126.com (X.L.)

2 Department of Prevention of Acute Infectious Diseases and Immunization, Xuhui Center for Disease Control and Prevention, Shanghai 200237, China

3 Department of Discipline Planning, Shanghai Jiao Tong University School of Medicine, Shanghai 200025, China

* Correspondence: wangsuping@shsmu.edu.cn (S.W.); caiyong202028@hotmail.com (Y.C.)

+ The two authors contribute equally to this study/work.

Citation: Gong, R.; Zhang, Y.; Long, R.; Zhu, R.; Li, S.; Liu, X.; Wang, S.; Cai, $Y$. The Impact of Social Network Site Addiction on Depression in Chinese Medical Students: A Serial Multiple Mediator Model Involving Loneliness and Unmet Interpersonal Needs. Int. J. Environ. Res. Public Health 2021, 18, 8614. https:// doi.org/10.3390/ijerph18168614

Academic Editors: Anise M. S. Wu, Phoenix K. H. Mo and Juliet Honglei Chen

Received: 6 July 2021

Accepted: 12 August 2021

Published: 15 August 2021

Publisher's Note: MDPI stays neutral with regard to jurisdictional claims in published maps and institutional affiliations.

Copyright: () 2021 by the authors. Licensee MDPI, Basel, Switzerland. This article is an open access article distributed under the terms and conditions of the Creative Commons Attribution (CC BY) license (https:// creativecommons.org/licenses/by/ $4.0 /)$.
Abstract: The use of social network sites (SNSs) is inevitable in daily life. Everyone is likely to be addicted to SNSs, especially medical students. This study is aimed to assess the degree of SNS addiction and its relation to psychosocial factors such as depression, loneliness and unmet interpersonal needs among Chinese medical students. The cross-section survey was conducted from March to May in 2018 in Shanghai Jiao Tong University School of Medicine. Of the total 1067 participants, $33.18 \%$ had an SNS addiction, $87.7 \%$ of the participants used SNSs every day during last month and $53.42 \%$ of the participants used SNSs for at least an hour per day during the last week. SNS addiction is positively related with depression both directly and indirectly. The mediating roles of loneliness and unmet interpersonal needs on the relationship between SNS addiction and depression are significant. For the well-being of medical students, efforts should be taken to prevent them from becoming addicted to SNSs.

Keywords: social network sites; SNS addiction; depression; loneliness; interpersonal needs

\section{Introduction}

Nowadays, social networking sites (SNS) are becoming increasingly popular around the world. SNSs are particularly attractive to most people, especially adolescents, for they cater to the needs of safety, association, estimation and self-realization [1], while they also create virtual spaces for seeking information, forming identity [2] and entertainment [3]. SNSs allow individuals to connect whenever and wherever possible, which also makes society increasingly inter-connected. While using SNSs brings benefits to individuals and society, they can also have negative effects, such as the problem of addiction. SNS addiction refers to a phenomenon that individuals driven by a strong motivation log on to SNSs and devote so much time and effort that it impairs other social activities, studies, work, interpersonal relationships, psychological health and well-being [4]. People may prefer online communication to face-to-face conversations, especially those with some low self-esteem. It will result in a continued and increased usage, with the consequence of neglecting offline interpersonal relationships and exacerbating psychological problems, including loneliness, depression and relationship dissatisfaction [4]. In order to cope with the resultant psychological problems, individuals will continue to engage in SNSs, which leads to a vicious cycle of addiction [5]. 
To some extent, almost the whole population are at risk of becoming addicted to SNSs. However, according to a meta-analysis of 10 studies worldwide, the prevalence of Internet addiction among medical students was five times higher than that of the general population [6]. The most important reason is that SNSs provide a virtual space for medical students to escape from great academic stress and social contacts since they are more vulnerable to negative psychological states (e.g., depression) [6]. A cross-sectional study conducted in India found that admittedly SNSs have their advantages, but in the present generation, the shortage dominates, especially for medical college students when considering academic performance, psychical health, mental health, social connection, etc. [7]. Up to now, there has been a lack of study on the relationship between SNS addiction and medical students in China.

Although we generally believe that SNS addiction is positively related to depression, different conclusions were drawn by several researchers on the same field. O'Keeffe first discovered "Facebook depression", which referred to developing depressive symptoms for excessive exposure to SNSs [8]. Jelenchick found no evidence supporting a relationship between SNS addition and clinical depression [9]. Moreover, when used as a mental health intervention for young people, SNSs could significantly decrease depressive symptoms [10]. In other words, SNSs are beneficial to depression, only if used appropriately. Once SNS addiction appears, the advantage will no longer exist. Thus, the interaction between SNS addiction and depression is complex. To dispose the dispute, we assume that there are both direct and indirect relations, while there are some factors mediating this indirect association.

Tracing the history of SNSs, it was developed based on the idea that people are linked with each other via six degrees of separation [11] and tried to promote society to be interconnected [12]. When technology makes individuals closer, more and more people feel "alone together", which is described as always being connected via technology while feeling isolated indeed [13], then it may result in more serious problems such as depression [14]. That means when becoming obsessed with contacting via SNSs, people would find that friendship seems less meaningful, and one may also consider that communicating with the desired people may be difficult under the influence of unwished friendship [15]. It would eventually cause those SNS addicts to feel alone and unsatisfied with their interpersonal needs. Given that the unmet interpersonal needs are a result of unfulfilled social competence and belonging needs [16,17], it has been reported to be bound up with loneliness, which emerges when there is a discrepancy between desired and real social relations [18], and depression.

In this study, we try to find out whether medical students' SNS addiction is more severe and related to psychosocial factors such as depression, loneliness and unmet interpersonal needs. Then, to better understand the relationship between SNS addiction and psychosocial factors, a serial multiple mediator model involving loneliness and unmet interpersonal needs will be built to examine the association between depression and SNS addiction based on following hypotheses:

Hypothesis 1 (H1). SNS addiction has substantial effects on depression, loneliness and unmet interpersonal needs.

Hypothesis 2 (H2). SNS addiction has both direct and indirect effects on depression, while loneliness and unmet interpersonal needs are mediators in the relationship between SNS addiction and depression.

\section{Materials and Methods}

\subsection{Participants}

A cross-sectional survey was conducted from March to May in 2018 at Shanghai Jiao Tong University School of Medicine. Those who met the following inclusion criteria were asked to participate: (1) aged above 18 years, (2) undergraduates, (3) proficiency in Chinese. 
Assuming a 30.0\% prevalence of SNS addiction in medical students [19], using an alpha of 0.05 and a relative error for sampling of 0.15 , we calculated a required sample size of 415 . Finally, 1067 valid questionnaires were collected without missing data among 1109 enrolled students.

\subsection{Ethics}

Written informed consent was obtained from every participant who agreed to be enrolled. First, graduate advisors agreed to distribute questionnaires in class. Then, trained investigators informed the participants about the background information on the survey (i.e., study goal, study procedure, anonymous protocol and potential risks) orally before the study began. During the recruitment, the participants were free to ask any question and to withdraw. Investigators were available for the explanation of any possible doubts while participants were filling in the questionnaire and responsible for the questionnaire collection.

\subsection{Measures}

\subsubsection{Demographic Characteristics}

Demographic characteristics including gender, enrollment time, major, frequency of SNSs usage during last month (per week) and length of SNSs usage during last week (per day) are investigated.

\subsubsection{Social Networking Sites Addiction Scale (SNSAS)}

The Chinese Social Networking Sites Addiction Scale was designed based on the six core symptoms of SNS addiction (mood modification, salience, tolerance, conflict, withdrawal and relapse) [20]. The validity of the SNSAS was examined in the pilot survey. Eight items (i.e., I tried to spend less time on SNSs, but I failed) answered on a 5-point Likert scale ranging from 1 ("strongly disagree") to 5 ("strongly agree") were included in this scale. A higher total score indicates a severer SNS addiction. The Cronbach's alpha was 0.854 .

\subsubsection{The 9-Item Patient Health Questionnaire (PHQ-9)}

Depression was measured using the 9-item Patient Health Questionnaire, a brief screening measurement that matches the diagnostic criteria in the Diagnostic and Statistical Manual of Mental Disorders, Fourth Edition [21]. The 4-point Likert scale inquired about the participants' frequency of depressive symptoms in the past 14 days (i.e., Over the last two weeks, how often have you been bothered by: Little interest or pleasure in doing things), ranging from 1 ("never") to 4 ("always"). A higher total score reveals a stronger sense of depression. The Cronbach's alpha was 0.902 .

\subsubsection{The 8-Item UCLA Loneliness Scale (ULS-8)}

The 8-item UCLA Loneliness Scale is a short version of the UCLA Loneliness Scale to assess one's degree of loneliness [22]. Item 3 (I am an outgoing person) and item 6 (I can find companionship when I want it) were revised before calculation. The 4-point Likert scale for each item ranges from 1 ("never") to 4 ("often"). A higher total score shows a deeper feeling of loneliness. The Cronbach's alpha was 0.800 .

\subsubsection{The 15-Item Interpersonal Needs Questionnaire (INQ-15)}

The 15-item Interpersonal Needs Questionnaire is a short scale for estimating one's unmet interpersonal needs [18]. Participants scored each item from 1 ("strongly disagree") to 7 ("strongly agree"). Item 7 (These days, other people care about me), item 8 (These days, I feel like I belong), item 10 (These days, I am fortunate to have many caring and supportive friends), item 13 (These days, I feel that there are people I can turn to in times of need) and item 14 (These days, I am close to other people) were revised before computing. 
A higher total score means greater dissatisfaction with unmet interpersonal needs. The Cronbach's alpha was 0.898 .

\subsection{Analysis}

IBM SPSS 22.0 and JASP 0.14.1.0 were used for analysis [23]. Descriptive statistics were performed using SPSS. Pearson correlation coefficient was used to test the association between variables. Mediation analysis was performed by JASP, which provides the model of total, direct and indirect effects with bootstrap confidence interval based on 1000 resamples. A $p$ value of 0.05 was considered statistically significant.

\section{Results}

\subsection{Demographic Characteristics of Participants}

The results of the descriptive statistics for the demographic characteristics of the participants are presented in Table 1. Of the total participants, 33.18\% (354/1067) had an SNS addiction, $87.72 \%$ of the participants used SNSs every day during the last month and $53.42 \%$ of the participants used SNSs for at least an hour per day during the last week. While gender and major did not show obvious relationships with SNS addiction, grade was significantly related to SNS addiction; compared to freshmen, juniors (Odds Ratio $(\mathrm{OR})=0.548,95 \%$ Confidence Interval $(\mathrm{CI})=0.388-0.774)$ and sophomores $(\mathrm{OR}=0.563$, $95 \% \mathrm{CI}=0.420-0.755)$ were less likely to be addicted to SNSs. The longer the SNSs usage time is, the more likely one would be addicted $(\mathrm{OR}=1.523,95 \% \mathrm{CI}=1.371-1.693)$.

Table 1. Demographic characteristics of participants ( $n, \%)$.

\begin{tabular}{|c|c|c|c|c|c|c|}
\hline \multirow{2}{*}{\multicolumn{2}{|c|}{$\begin{array}{l}\text { Demographic } \\
\text { Characteristics }\end{array}$}} & \multicolumn{2}{|c|}{ Number of Participants } & \multicolumn{2}{|c|}{$\begin{array}{l}\text { Had SNS } \\
\text { Addiction }\end{array}$} & \multirow[t]{2}{*}{$\mathrm{OR}^{\mathrm{a}}\left(95 \mathrm{CI} \%{ }^{\mathrm{b}}\right)$} \\
\hline & & $n / N$ & Column (\%) & $n / N$ & Row (\%) & \\
\hline \multicolumn{7}{|l|}{ Gender $^{\mathrm{c}}$} \\
\hline & Male & $447 / 1067$ & 41.89 & $149 / 447$ & 33.33 & $\begin{array}{c}0.988 \\
(0.763-1.279)\end{array}$ \\
\hline & Female & $620 / 1067$ & 58.11 & $205 / 620$ & 33.06 & - \\
\hline \multicolumn{7}{|l|}{ Grade $^{c}$} \\
\hline & $\begin{array}{l}\text { Senior and } \\
\text { above }\end{array}$ & $18 / 1067$ & 1.69 & $8 / 18$ & 44.44 & $\begin{array}{c}0.178 \\
(0.016-1.980)\end{array}$ \\
\hline & Junior & $203 / 1067$ & 19.03 & $80 / 203$ & 39.41 & $\begin{array}{c}0.548 \\
(0.388-0.774)^{* *}\end{array}$ \\
\hline & Sophomore & $351 / 1067$ & 32.90 & $136 / 351$ & 38.75 & $\begin{array}{c}0.563 \\
(0.420-0.755) * *\end{array}$ \\
\hline & Freshman & $495 / 1067$ & 46.39 & $130 / 495$ & 26.26 & - \\
\hline \multicolumn{7}{|l|}{ Major $^{c}$} \\
\hline & $\begin{array}{l}\text { Clinical } \\
\text { Medicine }\end{array}$ & $822 / 1067$ & 77.04 & $263 / 822$ & 32.00 & $\begin{array}{c}1.256 \\
(0.933-1.692)\end{array}$ \\
\hline & $\begin{array}{l}\text { Non-clinical } \\
\text { Medicine }\end{array}$ & $245 / 1067$ & 22.96 & $91 / 245$ & 37.14 & - \\
\hline \multicolumn{7}{|c|}{ Frequency of SNSs Usage During Last Month (Per Week) d } \\
\hline & Barely & $18 / 1067$ & 1.69 & $7 / 11$ & 38.89 & \\
\hline & 1 day & $11 / 1067$ & 1.03 & $2 / 11$ & 18.18 & \\
\hline & 2 days & $8 / 1067$ & 0.75 & $2 / 8$ & 25.00 & \\
\hline & 3 days & $9 / 1067$ & 0.84 & $4 / 9$ & 44.44 & 1.025 \\
\hline & 4 days & $10 / 1067$ & 0.94 & $1 / 10$ & 10.00 & $(0.925-1.136)$ \\
\hline & 5 days & $32 / 1067$ & 3.00 & $12 / 32$ & 37.50 & \\
\hline & 6 days & $43 / 1067$ & 4.03 & $11 / 43$ & 25.58 & \\
\hline & 7 days & $936 / 1067$ & 87.72 & $315 / 936$ & 33.65 & \\
\hline
\end{tabular}


Table 1. Cont.

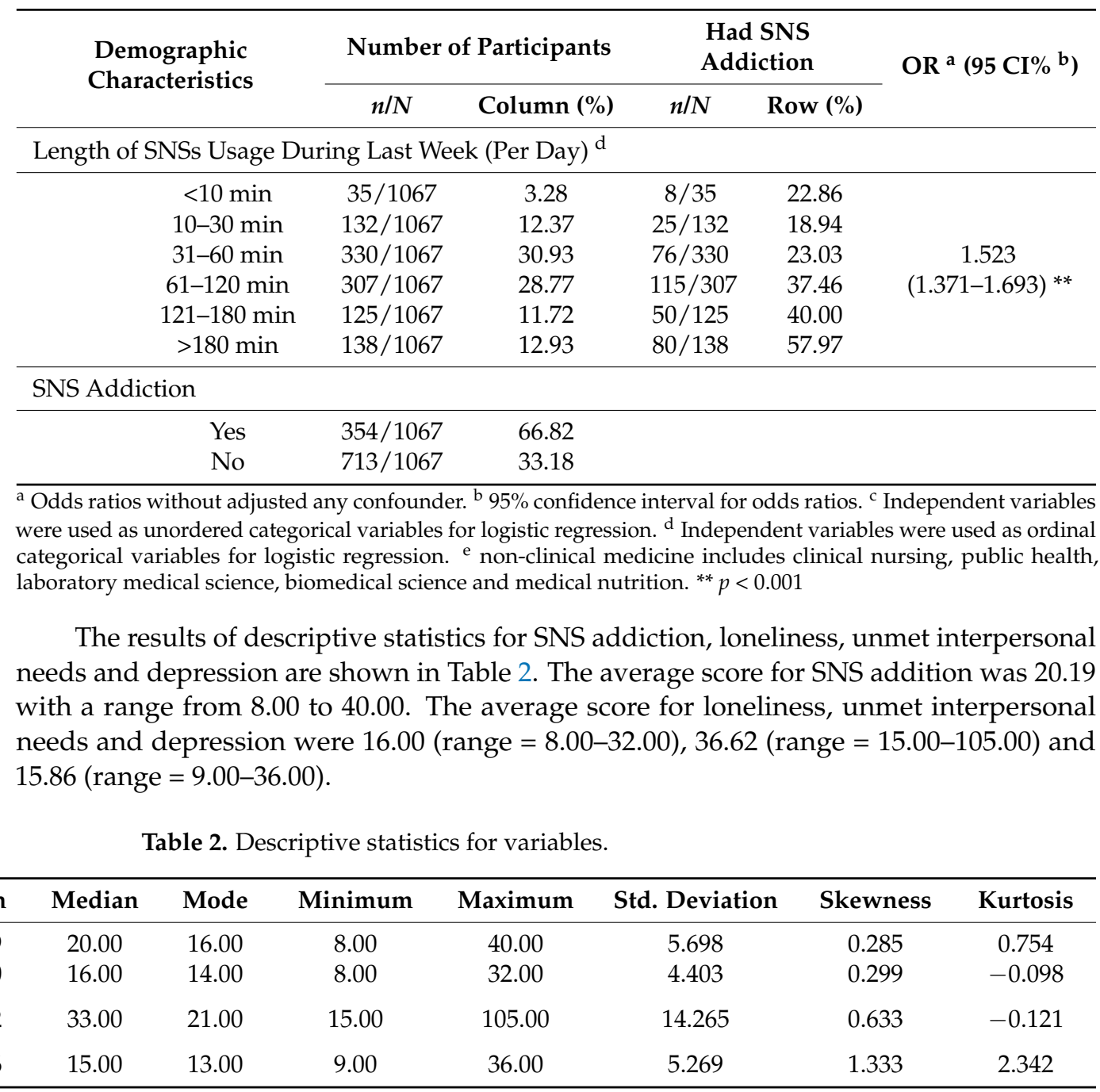

\subsection{Correlation Coefficients of Variables}

The results of Pearson correlation coefficients of SNS addiction, loneliness, unmet interpersonal needs and depression showed they are positively related to each other (Table 3).

Table 3. Correlations between variables.

\begin{tabular}{ccccc}
\hline Variables & $\begin{array}{c}\text { SNS } \\
\text { Addiction }\end{array}$ & Loneliness & $\begin{array}{c}\text { Unmet Interpersonal } \\
\text { Needs }\end{array}$ & Depression \\
\hline $\begin{array}{c}\text { SNS Addiction } \\
\text { Loneliness }\end{array}$ & - & $0.227^{* *}$ & $0.244^{* *}$ & $0.347^{* *}$ \\
Unmet Interpersonal & - & - & $0.614^{* *}$ & $0.439^{* *}$ \\
Needs & - & - & - & $0.469^{* *}$ \\
Depression & - & - & - & - \\
${ }^{* *} p<0.001$. & & &
\end{tabular}

\subsection{Serial Multiple Mediator Model}

The results of the mediation of loneliness and unmet interpersonal needs between SNS addiction and depression are described in Table 4 and Figure 1. The total effect is $0.061(p<0.001)$, the direct effect is $0.040(p<0.001)$ and the total indirect effect is $0.021(p<0.001)$. In addition, both of the two indirect effects are statistically signifi- 
cant: SNS addiction $\rightarrow$ loneliness $\rightarrow$ depression and SNS addiction $\rightarrow$ unmet interpersonal needs $\rightarrow$ depression.

Table 4. The mediation of loneliness and interpersonal needs between SNS addiction and depression.

\begin{tabular}{cccc}
\hline Path & Estimate & S.E. & 95\% C.I. \\
\hline Total effect & $0.061^{* *}$ & 0.005 & $0.048-0.072$ \\
Direct effects & $0.040^{* *}$ & 0.005 & $0.027-0.052$ \\
Indirect effects & & & \\
Total indirect effects & $0.021^{* *}$ & 0.003 & $0.015-0.027$ \\
Indirect 1 & $0.009^{* *}$ & 0.002 & $0.005-0.013$ \\
Indirect 2 & $0.012^{* *}$ & 0.002 & $0.008-0.017$ \\
Residual covariances & $0.558^{* *}$ & 0.034 & $0.488-0.634$ \\
\hline $\begin{array}{l}\text { Indirect 1: SNS addiction } \rightarrow \text { loneliness } \rightarrow \text { depression. } \\
\text { needs } \rightarrow \text { depression. }{ }^{* *} p<0.001 .\end{array}$ & & &
\end{tabular}
needs $\rightarrow$ depression. ${ }^{* *} p<0.001$.

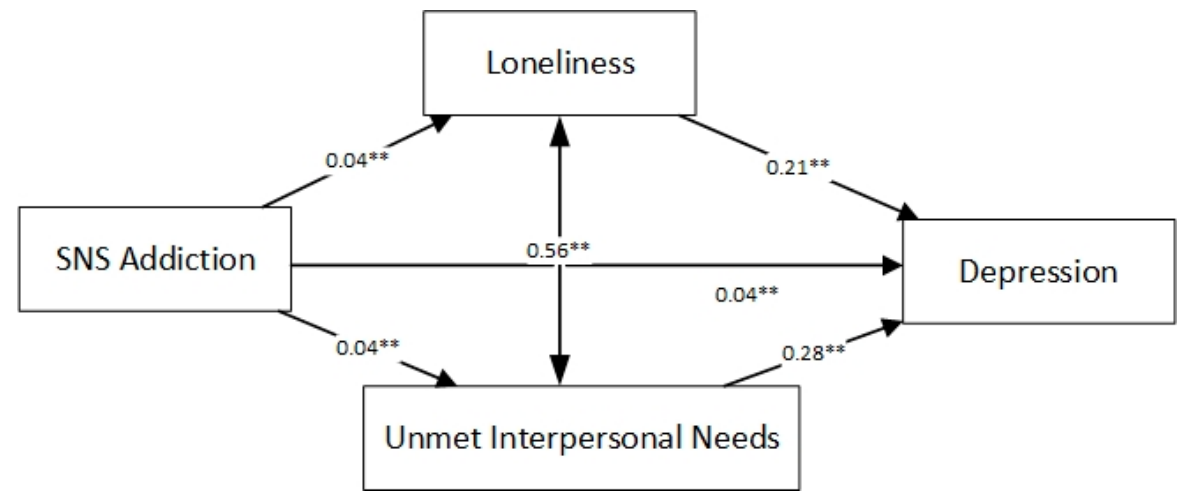

Figure 1. The serial multiple mediation of loneliness and unmet interpersonal needs between SNS addiction and depression. NOTE: Path coefficients were shown in standardized regression coefficients. ${ }^{* *} p<0.001$.

\section{Discussion}

The present study indicated that $33.18 \%$ of the participants had an SNS addiction. Most of the medical students used SNSs every day and half of them used them for over one hour a day. Among the demographic characteristics, grade was the only influencing factor. The mediator model was statistically significant and matched the hypothesis proposed above that SNS addiction would result in depression, both directly and indirectly, through the mediation of loneliness and unmet interpersonal needs.

Same as the previous studies conducted worldwide, the use of SNSs was pervasive among medical students [24]. One would feel more depressed as the reliance on SNSs becomes deeper [25]. Multitudinous research showed that the use of SNSs could supplement medical education [26], thus medical students were encouraged to engage in SNSs for sharing medical materials and contents [26]. However, a majority of medical students, similar to their peers, still used SNSs for personal purposes to escape from unpleasantness in real life [27]. Medical students are more susceptible to SNS addiction on account of receiving stressful and long-term education as well as suffering from economic pressure and fierce competition in life.

Consistent with our initial propose, SNS addiction has a moderate correlation with depression among Chinese medical students. Although previous research debated whether SNS usage could help relieve individuals' depression [28], SNS addiction did show a positive effect on depression in our study, which was consistent with several prior studies $[29,30]$. There are a couple of possible explanations for this. First, when people become addicted to SNSs, they are likely to be involved in a comparison in which they tend to underestimate themselves [31], resulting in depressive symptoms. On the other hand, when depressed, people may also dive into SNSs to fight the negative emotions. Second, 
when losing access to SNSs, SNS addicts will feel anxious and undergo a sleep quality drop [32], which can also lead to depressive symptoms. Therefore, SNS addiction interacts closely but complicatedly with depression.

The study also revealed that SNS addiction could influence depression through loneliness and unmet interpersonal needs, which can be explained as followed. First, SNS users have a stronger need for communication than those who do not use SNSs [33]. If the demand cannot be fulfilled, SNS addiction will appear. When addicted to SNSs, one will gradually give up real-world relationships, feeling lonelier and more unsatisfied with interpersonal needs [34,35], and finally depression emerges. More research is needed to further find evidence on the mediating role of loneliness and unmet interpersonal needs on the relationship between SNS addiction and depression, which is now facing a shortage.

Although this study covers all the majors and grades in medical school, it is still a single-center study. To better assess the status of SNS addiction among medical students, multiple centers are needed in the future. In the current study, we use cross-sectional data to establish a serial multiple mediator model. External verification and longitudinal studies are needed to verify the validity of the model. In addition, considering the complexity of social network addiction and psychological factors, a cohort study should be used to better explain the causal relationship.

\section{Conclusions}

The use of SNSs is inevitable in daily life, especially for medical students. When they apply SNSs, risks are still high for them to become addicted. Both direct and indirect associations are illustrated between SNSs and depression, and the mediating roles of loneliness and unmet interpersonal needs are significant. For the well-being of medical students, efforts should be taken to prevent them from becoming addicted to SNSs.

Author Contributions: Conceptualization, Y.C.; software, R.G.; formal analysis, R.G.; data curation, R.L., Y.Z., R.Z., S.L. and X.L.; writing-review and editing, R.G. and S.W.; supervision, S.W. All authors have read and agreed to the published version of the manuscript.

Funding: This work was support by SJTU Public Health School Local High-level University Achievement-oriented Top-notch Cultivation Programme for Undergraduate Students(18ZYGW21); Shanghai Three-year Action Plan for Public Health under Grant (GWV-10.1-XK18, GWV-10.2-XD13); Strategic collaborative innovation team (SSMU-ZLCX20180601).

Institutional Review Board Statement: The study was conducted according to the guidelines of the Declaration of Helsinki and approved by the Ethics Committee of Shanghai Jiao Tong University School of Medicine (SJUPN-201813).

Informed Consent Statement: Informed consent was obtained from all subjects involved in the study.

Data Availability Statement: The data presented in this study are available on reasonable request from the corresponding author.

Acknowledgments: We acknowledge all participants and interviewers involved in our research.

Conflicts of Interest: The authors declare no conflict of interest.

\section{References}

1. Riva, G.; Wiederhold, B.K.; Cipresso, P. The Psychology of Social Networking Vol. 1; De Gruyter Open Poland: Warsaw, Poland, 2016.

2. Zhao, S.; Grasmuck, S.; Martin, J. Identity Construction on Facebook: Digital Empowerment in Anchored Relationships. Comput. Hum. Behav. 2008, 24, 1816-1836. [CrossRef]

3. Barker, V. Older adolescents' motivations for social network site use: The influence of gender, group identity, and collective self-esteem. Cyberpsychol. Behav. 2009, 12, 209-213. [CrossRef] [PubMed]

4. Andreassen, C.S.; Pallesen, S. Social network site addiction-An overview. Curr. Pharm. Des. 2014, 20, 4053-4061. [CrossRef]

5. Griffiths, M.D.; Kuss, D.J.; Demetrovics, Z. Chapter 6-Social Networking Addiction: An Overview of Preliminary Findings, in Behavioral Addictions; Rosenberg, K.P., Feder, L.C., Eds.; Academic Press: San Diego, CA, USA, 2014; pp. 119-141.

6. Zhang, M.W.B.; Lim, R.B.C.; Lee, C.; Ho, R. Prevalence of Internet Addiction in Medical Students: A Meta-analysis. Acad. Psychiatry 2018, 42, 88-93. [CrossRef] 
7. Madaiah, M.; Seshaiyengar, C.; Suresh, P.; Munipapanna, S.; Sonnappa, S. Study to assess the effects of social networking sites on medical college students. Int. J. Community Med. Public Health 2016, 3, 1204-1208. [CrossRef]

8. O'Keeffe, G.S.; Clarke-Pearson, K. The impact of social media on children, adolescents, and families. Pediatrics 2011, 127, 800-804. [CrossRef] [PubMed]

9. Jelenchick, L.A.; Eickhoff, J.C.; Moreno, M.A. "Facebook depression?" social networking site use and depression in older adolescents. J. Adolesc. Health 2013, 52, 128-130. [CrossRef]

10. Ridout, B.; Campbell, A. The Use of Social Networking Sites in Mental Health Interventions for Young People: Systematic Review. J. Med. Internet Res. 2018, 20, e12244. [CrossRef]

11. Boyd, D.M.; Ellison, N.B. Social network sites: Definition, history, and scholarship. IEEE Eng. Manag. Rev. 2010, 38, 16-31. [CrossRef]

12. Kleinfeld, J.S. The small world problem. Society 2002, 39, 61-66. [CrossRef]

13. Turkle, S. Alone Together: Why We Expect More from Technology and Less from Each Other; Basic Books: New York, NY, USA, 2011.

14. Erzen, E.; Cikrikci, O. The effect of loneliness on depression: A meta-analysis. Int. J. Soc. Psychiatry 2018, 64, 427-435. [CrossRef] [PubMed]

15. Yoo, J.H. and E.J. Jeong, Psychosocial effects of SNS use: A longitudinal study focused on the moderation effect of social capital. Comput. Hum. Behav. 2017, 69, 108-119. [CrossRef]

16. Chu, C.; Buchman-Schmitt, J.M.; Stanley, I.H.; Hom, M.A.; Tucker, R.P.; Hagan, C.R.; Rogers, M.L.; Podlogar, M.C.; Chiurliza, B.; Ringer-Moberg, F.B.; et al. The interpersonal theory of suicide: A systematic review and meta-analysis of a decade of cross-national research. Psychol. Bull. 2017, 143, 1313-1345. [CrossRef] [PubMed]

17. Van Orden, K.A.; Cukrowicz, K.C.; Witte, T.K.; Joiner, T.E. Thwarted belongingness and perceived burdensomeness: Construct validity and psychometric properties of the Interpersonal Needs Questionnaire. Psychol. Assess. 2012, 24, 197-215. [CrossRef]

18. Heinrich, L.M.; Gullone, E. The clinical significance of loneliness: A literature review. Clin. Psychol. Rev. 2006, 26, 695-718. [CrossRef]

19. Tang, C.S.; Koh, Y.Y. Online social networking addiction among college students in Singapore: Comorbidity with behavioral addiction and affective disorder. Asian J. Psychiatr. 2017, 25, 175-178. [CrossRef]

20. Kuss, D.J.; Griffiths, M.D. Social Networking Sites and Addiction: Ten Lessons Learned. Int. J. Environ. Res. Public Health 2017, 14, 311. [CrossRef]

21. Manea, L.; Gilbody, S.; McMillan, D. A diagnostic meta-analysis of the Patient Health Questionnaire-9 (PHQ-9) algorithm scoring method as a screen for depression. Gen. Hosp. Psychiatry 2015, 37, 67-75. [CrossRef] [PubMed]

22. Hays, R.D.; DiMatteo, M.R. A short-form measure of loneliness. J. Pers. Assess. 1987, 51, 69-81. [CrossRef]

23. JASP Team. JASP (Version 0.14.1). 2020. Available online: https://jasp-stats.org/ (accessed on 14 August 2021).

24. Guraya, S.Y. The Usage of Social Networking Sites by Medical Students for Educational Purposes: A Meta-analysis and Systematic Review. North. Am. J. Med. Sci. 2016, 8, 268-278. [CrossRef] [PubMed]

25. Barman, L.; Mukhopadhyay, D.K.; Bandyopadhyay, G.K. Use of Social Networking Site and Mental Disorders among Medical Students in Kolkata, West Bengal. Indian J. Psychiatry 2018, 60, 340-345.

26. Cartledge, P.; Miller, M.; Phillips, B. The use of social-networking sites in medical education. Med. Teach. 2013, 35, 847-857. [CrossRef]

27. Guraya, S.Y.; Almaramhy, H.; Al-Qahtani, M.F.; Guraya, S.S.; Bouhaimed, M.; Bilal, B. Measuring the extent and nature of use of Social Networking Sites in Medical Education (SNSME) by university students: Results of a multi-center study. Med. Educ. Online 2018, 23, 1505400. [CrossRef]

28. Pantic, I. Online social networking and mental health. Cyberpsychol. Behav. Soc. Net. 2014, 17, 652-657. [CrossRef]

29. McDougall, M.A.; Walsh, M.; Wattier, K.; Wattier, R.; Miller, L.; Stevermer, M.; Fogas, B.S. The effect of social networking sites on the relationship between perceived social support and depression. Psychiatry Res. 2016, 246, 223-229. [CrossRef]

30. Yoon, S.; Kleinman, M.; Mertz, J.; Brannick, M. Is social network site usage related to depression? A meta-analysis of Facebookdepression relations. J. Affect. Disord. 2019, 248, 65-72. [CrossRef] [PubMed]

31. Blease, C.R. Too Many 'Friends,' Too Few 'Likes'? Evolutionary Psychology and 'Facebook Depression'. Rev. Gen. Psychol. 2015, 19, 1-13. [CrossRef]

32. Wolniczak, I.; Cáceres-DelAguila, J.A.; Palma-Ardiles, G.; Arroyo, K.J.; Solís-Visscher, R.; Paredes-Yauri, S.; Mego-Aquije, K.; Bernabe-Ortiz, A. Association between Facebook dependence and poor sleep quality: A study in a sample of undergraduate students in Peru. PLoS ONE 2013, 8, e59087. [CrossRef]

33. Sheldon, P. The relationship between unwillingness-to-communicate and students' Facebook use. J. Media Psychol. Theor. Methods Appl. 2008, 20, 67-75. [CrossRef]

34. Ranaeiy, S.; Taghavi, M.R.; Goodarzi, M.A. The Effect of Loneliness on Social Networking Sites Use and Its Related Behaviors. Glob. J. Health Sci. 2016, 8, 53672. [CrossRef] [PubMed]

35. Shettar, M.; Karkal, R.; Kakunje, A.; Mendonsa, R.D.; Chandran, V.M. Facebook addiction and loneliness in the post-graduate students of a university in southern India. Int. J. Soc. Psychiatry 2017, 63, 325-329. [CrossRef] [PubMed] 